\title{
Predicting business unit performance using employee surveys: monitoring HRM-related changes
}

\author{
Karina Van De Voorde, Tilburg University \\ Jaap Paauwe, Tilburg University and Erasmus University \\ Marc Van Veldhoven, Tilburg University \\ Human Resource Management Journal, Vol 20, no 1, 2010, pages 44-63
}

Organisations are increasingly using strategy tools such as workforce scorecards to keep track of human resource management related change processes that have been implemented and the effects of these on business unit performance. However, in this area, the challenge of finding appropriate indicators, establishing temporal relationships and providing useful management information still remains. Using longitudinal archival data from 171 branches of a large financial service organisation, this study examines to what extent employee surveys can serve as a predictor of better financial performance at the branch level. Results from a series of models in AMOS (Analysis of Moment Structures) showed that a significant part of branch profits could be predicted using employee surveys after correcting for prior profits. Based on extrapolation to all branches of this organisation, the changes in employee survey scores predict higher yearly profits of 178 million euros (17.9 per cent of the total yearly profits) across the entire company. Implications for research and practice are discussed.

Contact: Karina Van De Voorde, Department of Human Resource Studies, Faculty of Social Sciences, Tilburg University, PO Box 90153, 5000 LE Tilburg, The Netherlands. Email: f.c.v.d.voorde@uvt.nl

\section{INTRODUCTION}

$\mathbf{M}$ any organisations face a volatile market situation. In order to create and sustain competitive advantage in this type of environment, organisations must continually improve their business performance. Increasingly, organisations are recognising the potential of their human resources as a source of sustained competitive advantage. Linked to this, more and more organisations are relying on measurement approaches, such as workforce scorecards (e.g. Becker et al., 2001; Mayo, 2001; Phillips et al., 2001; Huselid et al., 2005), in order to gain insight into how the human resources in their organisation add value. These approaches focus mainly on improving the effective management of human resources in organisations (Paauwe, 2004). The increasing interest in measurement is further stimulated by a growing number of studies that show a positive relationship between human resource management (HRM) and organisational performance (Toulson and Dewe, 2004; Combs et al., 2006). In the context of this article, HRM refers to: 'all those activities associated with the management of people in firms' (Boxall and Purcell, 2008: 1).

Although the meta-analysis conducted by Combs et al. (2006) confirmed a relationship between HRM and performance at the company level of analysis, studies focusing on intermediate processes between HRM and performance at lower levels within the organisation remain scarce (Becker and Gerhart, 1996; Wright and Gardner, 2003). This dearth of studies raises difficulties because it remains unclear how human resources (employees) within an organisation add value (financial performance). Studies at the company level of analysis furnish 
information on the relationship between HRM and performance by comparing organisations that provide different products and services, and those that operate under different business conditions. Furthermore, company-level studies assume that there is no variation in HRM within a company. However, especially within large organisations, differences might exist between the designed practices at corporate levels and the implemented practices and employees' perceptions across business units (Nishii and Wright, 2008). Management activities usually occur at the business unit level. Critical outcomes for which managers are accountable are often located at this level. This is why there is a need for researchers to provide managers with information on the processes that are taking place within their company between HRM designed at corporate level on the one hand and organisational performance on the other. Management needs, in particular, this type of information in order to develop, implement and use workforce scorecards.

This study aims to explain performance differences between branches within a large company on the basis of employee survey data regarding HRM-related change processes. Our starting point was a dataset with two waves of employee survey and financial performance data from 171 branches of a large Dutch financial services organisation that had implemented renewed HRM policies aimed at improving branch performance. The company under study introduced a balanced scorecard type of measurement system in 2000 to provide branches with appropriate management information during the change process. Financial data were derived from objective registrations of financial transactions, and employee data were derived from employee survey research.

The main contribution of this study is to demonstrate how organisations can monitor HRM-related change processes using employee surveys. Our contribution consists of tackling three challenges facing corporate HR managers and HR researchers when setting up and making use of workforce scorecards (Fischer and Mittorp, 2002). First, the human resources component may be the most difficult area for which to find good business unit-level indicators (Ulrich, 1997; Mayo, 2001). The next challenge researchers face is to make temporal inferences between HRM indicators and business outcomes (Wright et al., 2005). Finally, the established relationships have to be translated into relevant management information (Becker and Gerhart, 1996). Each of these three challenges will be discussed later in more detail. Following a brief introduction presenting these challenges, we then focus on how we addressed these challenges in the present study.

\section{Employee survey data as HRM-related change process indicators}

Management needs to select and develop a range of indicators that can be used to monitor and measure the effects of HRM (Paauwe, 2004). Two of the main discussion points relating to HRM measurement concern the content and time horizon of measures (Pfeffer, 1997; Paauwe, 2004).

As far as content is concerned, most HRM indicators focus on costs, such as salary costs. However, these indicators do not inform us about what is being accomplished, nor do they inform us about how value is added (Pfeffer, 1997; Paauwe, 2004). This type of indicator only measures the expenditure of resources and does not measure implemented HRM policies or their impact. The present study compares branches within a large organisation. In order to focus on performance-enhancing factors at this level rather than on indicators relating to costs, we refer to the process models developed by Nishii and Wright (2008) and Boxall and Purcell (2008). These models describe the HRM-performance linkage as follows: intended HRM practices (policies developed by decision-makers) influence actual HRM practices (implemented HRM practices), employees perceive these practices (perceptions of HRM practices) and react to them (employee outcomes), and these employee outcomes result in 
organisational performance. Implemented HRM practices and employee perceptions play a central role in these process models: they are proposed as a linking mechanism within the company between intended HRM at company-level and organisational performance.

It is possible to identify HRM indicators by asking HR professionals or line managers about the HRM practices in their branch. However, questions have been raised as to whether HR professionals or line managers can provide an accurate description of the implemented practices in a branch (Gerhart et al., 2000). Although HR professionals can report on the proportion of employees that are covered by a certain HR practice, for example, training, this does not provide us with accurate information about the extent to which employees experience an opportunity for development (Gerhart, 2005). In order to exert effects, HRM practices need to be perceived and interpreted subjectively by employees (Nishii et al., 2008).

With regard to the timescale of the measurements, new HRM activities are usually assessed over a very brief period of time, whereas it may be years before their effects manifest (Paauwe, 2004). Wright and Haggerty (2005) argued that it takes almost two years to design and deliver new HRM practices, and another one or two years before these practices have an effect on organisational performance. In this context, a positive feature of measuring employees' perceptions via surveys in comparison with measuring designed or implemented HRM practices using management interviews is that these perceptions are more closely linked to performance. Narrowing the length of the linkage between HRM and organisational performance, by including more proximal indicators of HRM and performance (in this study: employee perceptions and business unit outcomes), will probably result in stronger relationships because fewer other factors intervene (Guest, 1997). Moreover, given that it might take a considerable amount of time before intended HRM policies have an effect on performance, more proximal indicators reduce the length of the time interval that is needed to detect a relationship in research. Hence, in this study, we use employee survey data to monitor processes driven by HRM-related interventions.

\section{Temporal inferences}

The next challenge researchers face is to make temporal inferences between interventions and outcomes. In other words, do new HRM policies actually result in higher organisational performance? Based on Cook and Campbell (1979), Wright et al. (2005) presented three criteria for establishing causal relationships: covariation between cause and effect, time precedence and the possibility of controlling for or ruling out alternative explanations for a relationship. The most rigorous causal test takes the form of an experiment that would require two comparable organisations with respect to the implemented HRM policies and performance: one willing to implement a totally new HRM system and the other one willing to make no changes at all, a mission impossible for any researcher.

With regard to time precedence, the most common research design in the literature is a cross-sectional design (e.g. Guest, 2001; Wright et al., 2005). There are a limited number of longitudinal studies in the HRM-performance field controlling for prior or concurrent performance (e.g. Guest, 2001; Wright et al., 2005). However, making temporal inferences requires both measurement of HRM and performance over time (Guest et al., 2003). In order to control for 'stability' in HRM and performance, we need at least two waves of data. It is important to control for stability in HRM and performance because it can be expected that business units with high scores on HRM and performance in relation to other business units at a certain time point will retain similar relative positions at a follow-up time point. Without controlling for these prior scores, we cannot conclude that substantially changed HRM policies actually have resulted in increased performance. 
Three exceptions using two waves of employee survey data, as well as performance data, can be found in the literature. First, Koys (2001) investigated the link between employee attitudes, behaviours and business outcomes for 28 branches of a regional restaurant chain. He presented evidence that employee attitudes and behaviours in year 1 influenced organisational outcomes in the following year more strongly than organisational outcomes in year 1 influenced employee attitudes and behaviours in the following year. Controlling for year 1's profitability, the HR outcomes of satisfaction, organisational citizenship behaviour and turnover measured at year 1 explained an additional 17 per cent of variance in year 2 profitability. Schneider et al. (2003) investigated employee perceptions and attitudes in combination with financial performance data (return on assets and earnings per share) from 35 companies operating in different sectors over eight years. They found significant and stable relationships for 3 out of 7 scales across various time lags. However, overall job satisfaction and satisfaction with security were more strongly predicted by past performance than in the reverse analysis. Satisfaction with pay exhibited a reciprocal relationship with performance measures. Schneider et al. (2003) and Koys (2001) used multiple data waves; however, the sample size was low in both studies. Moreover, Koys (2001) only used prior performance as a control variable and Schneider et al. (2003) only reported bivariate correlations. Neither of the authors applied structural equation modelling. Only Ryan et al. (1996) applied a cross-lagged analysis that allows for a simultaneous estimation of temporal relationships between variables in this field of study. They reported a study that used data from 142 branches in a car finance company over two consecutive years. They found several significant relationships between employee attitude factors and performance in successive years, although they also unexpectedly found that customer satisfaction in year 1 predicted employee satisfaction in year 2 but not vice versa.

As can be seen from this short summary of longitudinal studies using two data waves, mixed evidence has been found on temporal relationships. The lack of longitudinal studies is thus problematic in HRM-performance research. Furthermore, several explanations for reversed or reciprocal causation have been proposed. First, organisations with high profits might reveal a greater willingness to invest in HRM, resulting in more positive employee perceptions than those that do not have high profits (Siehl and Martin, 1990; Paauwe and Boselie, 2005). In addition, a high performance may also signal organisational health and thus, employment security (Paauwe and Boselie, 2005), again having an upwards influence on employee perceptions. This study therefore uses a longitudinal design: linkages between employee survey data and performance at two time points are investigated.

\section{Useful management information}

The final challenge researchers face is providing useful management information. By relying on significance tests and explained variances for the established relationships between employee survey data and performance, the results of the studies are difficult to interpret by practitioners. These kinds of statistical parameters are common in social sciences (e.g. Ryan et al., 1996; Koys, 2001; Gerhart, 2007) but are less well known among managers. A consequence might be that organisational decisions are not based on the best available academic evidence. This is unfortunate because even small significant effect sizes might translate into substantial amounts of money (Ryan et al., 1996). Comparing the top and bottom quartiles in terms of employee attitudes, Ryan et al. (1996) concluded that branches within the top versus the bottom quartile have a 15 per cent difference in market share. However, it should be noted that temporal order in the relationship between attitudes and performance was not demonstrated in that study.

There is a need to translate research evidence into information that can be used by managers and policy-makers within organisations to solve organisational problems. This process is 
known as 'evidence-based management' (Rousseau, 2006). As a starting point for this process, a meaningful index is needed to describe policy-relevant effect sizes (Becker and Gerhart, 1996). For example, the practical influence of the results of studies carried out by Huselid et al. (1997) and Huselid (1995) was assessed by calculating the effect of a one standard deviation increase in an HRM effectiveness scale on their performance outcomes. However, to report policyrelevant effect sizes is not enough; in addition, researchers need to reflect on the feasibility for an organisation or branch of increasing their scores on HRM with one standard deviation (Gerhart, 2007). This could be accomplished, for example, by reporting how frequently such organisations or branches are found in the research population. In this study, we will check the feasibility of obtaining such increases in HRM measures by determining the percentage of branches that have already attained a one-standard deviation increase in employee survey scores during the research period.

\section{This study}

This study investigates longitudinal relationships between employee surveys and branch performance. Using employee survey data as a possible indicator, we focus on perceptions of HRM-related change processes as rated by multiple employees within a branch. Two waves of data are used to test the assumed temporal relationship, thus taking into account a possible reversed sequence. Finally, this study uses an extrapolation method to translate our findings (estimates) into relevant management information (in this case, increase in profits in terms of euros).

\section{The company under study}

The company under study is a large financial services organisation, serving more than 9 million private individuals and corporate clients in the Netherlands. The financial services organisation has the highest credit rating (Triple A) and is among the world's 15 largest financial institutions (in terms of Tier capital 1). Despite the stagnating economy in 2002, its net yearly profits increased during the research period from 2000 to 2005. During the research period, the company was composed of approximately 300 local (domestic) independent branches plus their central organisation as well as its international subsidiaries. It employed approximately 55,000 staff and was represented in 37 countries. The focus of this research is on the Dutch domestic branches. The company has a cooperative structure, which means that the branches are members and shareholders of the supralocal cooperative organisation that advises the branches and supports their local service. Each branch sphere of activity is limited to its own direct area, fostering close involvement with local customers. The ambition of the domestic branches is to be the largest, best and most innovative financial service provider in the Netherlands. To create customer value, they aim to provide better and more appropriate financial services to their clients compared with their competitors. They also aim to ensure continuity in the services provided with a view on the long-term interests of their clients. Finally, they show commitment to clients and their clients' living environments so that the organisation can contribute to achieving the clients' ambitions.

During the research period (2000-2005), the market changed. On the one hand, customers wanted more differentiated and specialised financial services and wanted to conduct their banking business any time and anywhere. On the other hand, competition increased as a result of the following: mergers between other financial service institutions, an increase in market transparency, an increase in distribution channels and the market entry of new financial services suppliers. In order to remain competitive, the organisation has made changes in market 
strategy, organisation structure and operating systems. The aim of these interventions was to achieve market leadership and to improve cost-effectiveness while maintaining cooperative values.

The corporate organisation played a facilitating role and advised the local subsidiaries on how to achieve these new corporate objectives. The cooperative organisation designed new HR policies aimed at improving business unit-level productivity because this outcome is the most important way for all branches to contribute to the overall company objectives. To provide the branches with the appropriate management information that would enable them to keep track of HRM policy changes within their branch, an updated type of scorecard system was designed. This system facilitated a branch comparison of HRM policy changes and of outcomes. The implementation of the renewed HRM policies and also the interpretation of these by employees may differ among the branches because all these independent, self-governed local branches are to a large extent, autonomously responsible for shaping new HRM policies within their branch.

In this research, six employee survey dimensions were selected. These employee survey dimensions were chosen primarily because they are evaluative of the intended HRM policies and the enacted HRM activities as developed by the corporate organisation to enhance productivity. We expected that these employee survey dimensions would change during the research period, driven by the renewed HRM policy. Although the selection of dimensions might seem company- or industry-specific, these dimensions reflect some of the underlying processes of HRM as described by Boxall and Purcell (2008). Boxall and Purcell (2008) distinguish two processes: management implements HR policies aiming to build ability, motivation and opportunity to perform at the individual level, and workforce capabilities, work organisation and work attitudes at the collective level; management articulates values to influence employee perceptions. Moreover, the selected HR dimensions are very commonly used in current HR research (Boselie et al., 2005). Each of the survey dimensions is discussed in the next section in more detail.

The most important emphasis of the renewed HRM policy was on the values articulated by management. The values articulated by management refer to a desired way of working with employees, customers and suppliers related to the organisation's mission and values (Boxall and Purcell, 2008). The organisation under study aimed to improve cost-effectiveness while still providing customer quality. By communicating and sharing information on these goals with employees, they can align their efforts and behaviours with the strategy. In order to assess the extent to which employees are aware that quality and effectiveness are given priority in their branch and to monitor the extent to which the branch communicates clearly about these goals, we selected three indicators: quality orientation, goal effectiveness and information sharing.

The renewed HR policy stimulates investment in employee development; this provides a branch with a capable workforce. Training and development practices are aimed at increasing employees' knowledge, abilities and skills to perform. Particularly, in a highly competitive situation, employees need to be constantly learning, for example, by being given information about new products and new selling techniques. For this reason, as a fourth important employee survey dimension, we selected employee attitudes regarding the extent to which the business unit and supervisors in the business unit offer opportunities for development.

A third component of the renewed HR policy concerns a number of performance management initiatives related to the motivational component of HRM. As a result of the changes in the operating system, job functions are more clearly classified. This classification promotes differentiation based on employee performance. A salaried pay system with yearly increments has been supplemented by a bonus pay system. There is a chance that job insecurity will increase as a result of job and task design changes. However, employees who show a good 
performance compared with employees who show an unsatisfactory performance will be rewarded accordingly and will face fewer threats to job security. Job security constitutes an important HRM aspect in the Dutch context (Boselie et al., 2001), and furthermore, we expected that the performance of a branch was positively related to job security. In sum, we expect a positive productivity effect from the performance management policies introduced in the company. In this study, therefore, we included two employee survey elements to tap into these aspects, i.e. pay satisfaction and job security.

\section{METHODS}

\section{Subjects}

Employee survey data from 2000-2005 were used and 171 branches participated in the employee survey system on two occasions between 2000 and 2005 (43 per cent of the total population, data as of 2003). Driven by the nature of the data collected in ongoing business practice, different time intervals between the two measurement points exist (one-, two- and three-year intervals). The average interval between the employee surveys is 2.1 years (with a standard deviation of 0.61 ). This time lag reflects prior research on attitudes and performance (Ryan et al., 1996). Employee survey data from 2000, 2001, 2002, 2003 and 2004 were used for time point 1 (T1), and employee survey data from 2001, 2002, 2003, 2004 and 2005 were used for time point 2 (T2). At both time points, employee survey data and productivity were coupled contemporaneously. For example, we linked the survey and productivity data for 2001 to the year-end productivity records for 2001 (see Figure 1).

At T1, questionnaire data on 14,477 employees were available. The average response rate in the employee surveys at the branch level was 77.5 per cent. The average number of participants per branch was 84.7. At T2, questionnaire data on 14,860 employees were available. At the branch level, the average response rate in the employee surveys was 84.7 per cent. The average number of participants per branch was 86.9.

FIGURE 1 Research design

\begin{tabular}{|c|c|c|}
\hline $\begin{array}{l}\text { Time point } 1 \\
2000(38), 2001(73), \\
2002(45), 2003(14), \\
2004(1)\end{array}$ & & $\begin{array}{l}\text { Time point } 2 \\
2001(3), 2002(29), \\
2003(66), 2004(58), \\
2005(15)\end{array}$ \\
\hline Employee survey & & Employee survey \\
\hline $\begin{array}{l}\text { Concurrent } \\
\text { profits/FTE }\end{array}$ & & $\begin{array}{l}\text { Concurrent } \\
\text { profits/FTE }\end{array}$ \\
\hline \multicolumn{3}{|c|}{$\begin{array}{l}\text { Time interval } \\
1 \text {-year }(25) \\
\text { 2-years }(106) \\
3 \text {-years }(40)\end{array}$} \\
\hline \multicolumn{3}{|c|}{${ }^{\mathrm{a}}$ Number of branches is given in parentheses } \\
\hline
\end{tabular}


Although branch participation in the survey system was not compulsory, participation was strongly promoted by the supralocal organisation and could be seen as part of the regular way of managing employees within this organisation. To exclude selectivity of the sample, we checked the representativeness of the sample (T1 data as of 2001, T2 data as of 2003) at both the branch and the individual level.

At branch level, representativeness of the sample for the total population in the organisation was checked in terms of region in the Netherlands, and branch size. At the individual level, representativeness was checked in terms of age class (five levels: 25 years and under, 25-35 years, 35-45 years, 45-55 years and 55 years and older), number of working hours per week (under 36 hours, 36 hours, over 36 hours) and gender. We found that the sample could be regarded as representative for the total organisation at both levels and both time points in terms of the variables mentioned; the difference between our sample and the population was at a maximum five per cent for each category of the previously mentioned variables.

\section{Measures}

Survey scales As discussed earlier, we selected six employee survey dimensions in line with the HRM literature and the associated change processes: quality orientation, goal effectiveness, information sharing, pay satisfaction, job security and development. The scales for quality orientation, goal effectiveness and information sharing were subsequently grouped together. We have termed this dimension 'performance orientation'; these scales reinforce desired employee behaviours by communicating the business goals so that employees can align their behaviours towards this goal. Given that these scales were highly correlated (0.67 to 0.81 ), bundling them reduces the possibility of multi-collinearity in the analyses.

In this study, bank branches were the unit of analysis. To support the aggregation of individual survey scores to branch-level scores, we calculated intraclass correlations (ICC1 and ICC2) and tested whether average scores differed significantly across branches. The ICC1 can be defined as the amount of variance in individual employee scores attributable to the branch they work for (Klein et al., 2000). The ICC2 parameter can be interpreted as the reliability of comparisons between mean branch scores. Values above 0.70 were considered good; values above 0.50 were deemed tolerable (Klein et al., 2000). We also calculated Rwg (J) values of within-branch agreement (James et al., 1984) for each survey score, to further justify the aggregation of our survey scores to the branch level. Values of 0.70 were considered sufficient for aggregation. In Table 1, the aggregation characteristics at the two time points were listed.

As can be seen from Table 1, the ICC 1 values are between 2 and 10 per cent. These intraclass correlations are comparable with the lowest intraclass correlations reported in other studies

TABLE 1 Aggregation characteristics

\begin{tabular}{|lcccccr|}
\hline Survey scale & ICC1 & & ICC2 & & Rwg & T2 \\
& T1 & T2 & T1 & T2 & T1 & \\
Performance orientation & 0.10 & 0.09 & 0.90 & 0.90 & 0.85 & 0.87 \\
Development & 0.04 & 0.04 & 0.78 & 0.80 & 0.70 & 0.69 \\
Pay satisfaction & 0.05 & 0.02 & 0.81 & 0.68 & 0.80 & 0.82 \\
Job security & 0.04 & 0.03 & 0.78 & 0.75 & 0.49 & 0.51 \\
\hline
\end{tabular}


conducted at the organisation level (Schneider et al., 2003). These values certainly are not high, but low to modest ICC1 values are in themselves not problematic if the number of cases is large enough. With the number of individual respondents available for this study, it was found that for all four survey scores, the variance components attributable to the branch were statistically significant in an F-test $(p<0.001)$. We obtained good ICC2 values for all four dimensions. For performance orientation, pay satisfaction and development, the Rwg (J) values suggest sufficient within-branch agreement to justify aggregation to the branch level (the Rwg (J) values are between 0.69 and 0.87). For job security, we found only moderate support. The Rwg (J) scores for this dimension are 0.49 (T1) and 0.51 (T2). These relatively low scores might be caused by the limited number of items and answer categories for this particular scale.

All in all, we believe that reliable comparisons between mean values for branches are possible, even if the ICC1 values we found are rather small (Klein et al., 2000). The measures for the four subdimensions are described in the next sections.

\section{Performance orientation}

Performance orientation consists of quality orientation, goal effectiveness and information sharing. Quality orientation, goal effectiveness and information sharing are three scales based on to the Dutch FOCUS questionnaire (Van Muijen et al., 1996), which measures organisational climate. This instrument is based on Quinn's competing values approach (Quinn and Rohrbaugh, 1983). The item content is comparable to the quality scale, the clarity of organisational goals scale and the reflexivity scale in the Organisational Climate Inventory inspired by the same competing values model (Patterson et al., 2005). A sample statement from the quality orientation scale is, 'This branch is aimed at achieving high quality products to our internal and external customers.' A sample statement from the goal effectiveness scale is, 'In this branch we are aware of costs and act accordingly.' A sample statement from the information sharing scale is, 'I am sufficiently informed about branch goals.' Respondents rated each of the items on a five-point scale ranging from 'I completely agree' to 'I completely disagree'. The Cronbach's alpha scores for this dimension are 0.84 (T1) and 0.83 (T2).

\section{Pay satisfaction}

This five-item scale was constructed by Van Veldhoven and Meijman (1994). The item content is derived from Smith et al. (1969) and Hackman and Oldman (1975). Using a four-point response scale (always, often, sometimes and never), the respondents are asked to evaluate current pay. A sample question for this scale is, 'Do you think you are fairly paid in comparison to others within this organisation.' The Cronbach's alpha scores for this scale are 0.79 (T1) and 0.66 (T2).

\section{Job security}

This four-item scale was constructed by Van Veldhoven and Meijman (1994). The scale asks respondents to rate their need for more security with regard to several job attributes, such as the continuity of their contract or their job status. Items are assessed using a four-point response scale (always, often, sometimes and never). A sample item is, 'Do you need more certainty that your current branch will still be in existence in one year's time?' The Cronbach's alpha scores for this scale are 0.94 at both time points.

\section{Development}

This scale consists of two items. The first item asks respondents to rate the general tendency of their leader to stimulate the development of their talents on a five-point response scale (I 
completely agree, I somewhat agree, neutral, I somewhat disagree, I completely disagree). The second item concerns the extent to which the organisation offers opportunities for work-related training. This item was assessed using a four-point response scale (always, often, sometimes and never). Standardised (between 0 and 100) item scores were averaged to get a development dimension score. The Cronbach's alpha scores for this scale are 0.41 (T1) and 0.38 (T2).

To ease the interpretation, all survey dimensions have been scored in such a way that high scores indicate a situation that is generally considered favourable to the employee.

Productivity In this study, productivity was operationalised by means of a yearly 'branch profit per time equivalents (FTE) index'. Profits were operationalised as gross profits minus return on equity. We chose this parameter because it is not influenced by differences in sales/costs between the branches and because it only reflects that part of profit that is not related to return on equity. The number of FTEs was determined on the basis of the average number of FTEs working at a local branch during a specific year. Both parameters were provided from the regular yearly financial/HR reports within the organisation made available by the finance and control/HR department. These reports are based on objective registrations of personnel and financial transactions.

\section{Analysis}

To test relationships between employee survey dimensions and productivity, we used structural equation modelling in AMOS 6 (Arbuckle, 2005). This approach enabled us to analyse the effects of the employee survey dimensions (T1 and T2) on productivity (T1 and T2) while controlling for temporal stabilities (effects between identical variables measured at T1 and T2) and inverse causation (productivity T2 influences survey dimensions at T1). Employee survey dimensions were allowed to covary at $\mathrm{T} 1$ and $\mathrm{T} 2$. Considering the proportion of the number of survey scale items on the one hand to the number of cases at branch level on the other, we decided to include the survey dimension scores as manifest variables rather than as latent variables in our model in order to maintain a favourable indicator-to-sample size ratio.

The significance of the effects was determined by comparing the probability level $(p)$ from the critical ratio - calculated by dividing the parameter estimate by its standard error - using a significance level of 0.05 . We used the chi-square $\left(\chi^{2}\right)$, root mean square error of approximation (RMSEA), adjusted goodness of fit index (AGFI) and Bentler's comparative fit index (CFI) to assess the fit of the model as described by Byrne (2001). Non-significant $\chi^{2}$, AGFI and CFI values above 0.90 , and RMSEA values below 0.05 indicate a good fit between model and data.

Finally, in order to obtain a more parsimonious model and a clearer indication of which survey dimensions have an effect on productivity, we excluded the non-significant effects following a backwards elimination procedure. We controlled for the length of the time interval between the two employee surveys within a branch (measured in months) as the length of the time interval could be a confounding factor. We applied a $\chi^{2}$ difference test to determine whether this constrained model fitted the data just as well as the full model.

Next, we estimated the practical significance of the effect of survey scores on productivity by calculating the effect of a one-standard deviation increase in survey scores on profits/FTE at $\mathrm{T} 2$, but we did so only for survey dimensions that showed a significant positive effect on productivity at $\mathrm{T} 2$. We then calculated the change relative to the mean productivity for these dimensions. Next, we determined how much (calculated in euros) of the yearly financial performance can be predicted by survey scores, first, by extrapolating this percentage to our 
sample of 171 branches and second, by extrapolating this percentage to the total research population (e.g. all local domestic branches in the Netherlands). The extrapolation to the total research population was based on overall firm performance data for 2003, the median year for T2.

\section{RESULTS}

\section{Descriptives}

Table 2 shows the means and standard deviations at both time points and the correlations among survey dimensions and profits/FTE. Table 2 shows that the mean scores for the survey dimensions of performance orientation and pay satisfaction increased across the two time points. The mean scores for job security and development decreased across the two time points. Furthermore, the survey dimensions of job security and development are moderately stable across time (around 0.40). Pay satisfaction and performance orientation have a relatively high stability (0.62 and 0.51). At T1 (average productivity of 23.391 euros/FTE), the branches performed less well than at T2 (average productivity of 33.216 euros/FTE). This reflects economic reality for financial services organisations where profits are influenced to a large extent by external factors relating to market trends. The bivariate correlation between T1 and $\mathrm{T} 2$ is 0.62 , however, which suggests that the financial position at T1 is fairly predictive of the financial position at T2. Finally, Table 2 shows that the survey dimensions are at least at one time point significantly correlated with profits/FTE. This is a first sign that these survey dimensions are performance-related indicators.

\section{Effects between survey dimensions and performance}

We began the structural equation modelling analyses by testing the full model. Two fit indices of this model indicated a reasonable fit $\left(\chi^{2}=28.6 ; p=0.00 d f=12\right.$; AGFI $\left.=0.86\right)$. Only the CFI $(\mathrm{CFI}=0.97)$ suggested a good fit. We trimmed this model by deleting non-significant associations (backwards elimination). This second model showed better fit measures $\left(\chi^{2}=37.9\right.$; $p=0.02 d f=22 ;$ AGFI $=0.90 ; \quad C F I=0.97 ; \quad$ RMSEA $=0.065)$. Moreover, a $\chi^{2}$ goodness-of-fit statistical test showed that this constrained model fits just as well as the full model $\left(\Delta \chi^{2}=9.23\right.$; $\Delta d f=10 ; p>0.10)$. The second model is preferred because it is more parsimonious than the first model. ${ }^{1}$

In this revised model, five forward causation effects are significant $(p<0.05)$. Performance orientation is positively associated with profits/FTE at T1 and at T2 $(\beta=0.37 ; \beta=0.22 ; p<0.05)$, indicating that the branches with high scores on performance orientation have more profits/ FTE and that an increase in performance orientation is associated with an increase in profits/FTE. With regard to pay satisfaction, a relationship was found between pay satisfaction at $\mathrm{T} 1$ and profits at $\mathrm{T} 2(\beta=0.20 ; p<0.05)$, indicating that pay satisfaction scores at $\mathrm{T} 1$ are positively associated with an increase in profits/FTE. It was found that development is negatively associated with profits/FTE at T1 $(\beta=-0.34 ; p<0.05)$; branches with high scores on development show less profits/FTE. It was found that job security was positively related to profits/FTE at T2, indicating that an increase in job security is associated with an increase in profits/FTE ( $\beta=0.12 ; p<0.05$ ). We found only one significant positive inverse causation effect and that was between profits/FTE and job security $(\beta=0.18 ; p<0.05)$. The higher the profits/ FTE in a branch at T1, the more job security employees experience at T2. The results of the revised model are presented in Figure 2. The revised model explains 49 per cent of the variance in profits/FTE at T2. The biggest part of this percentage (38.2 per cent) is attributable to the 


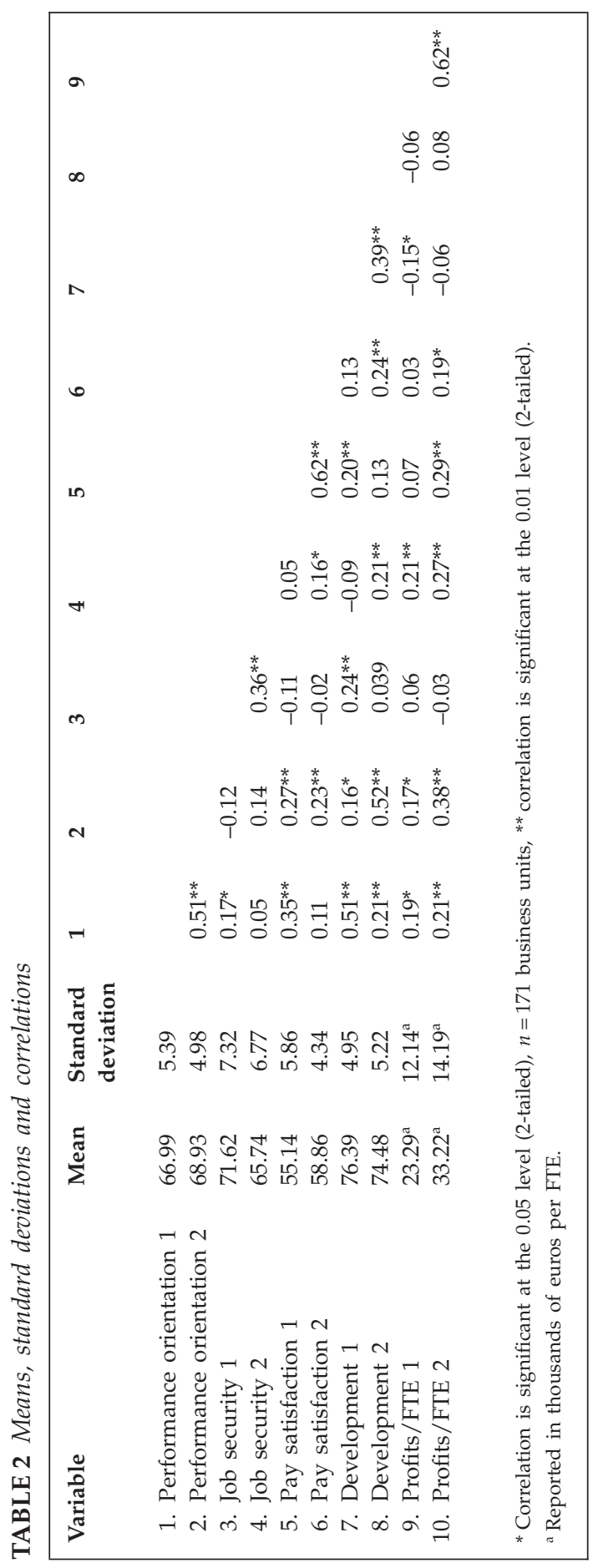


FIGURE 2 Results of revised model

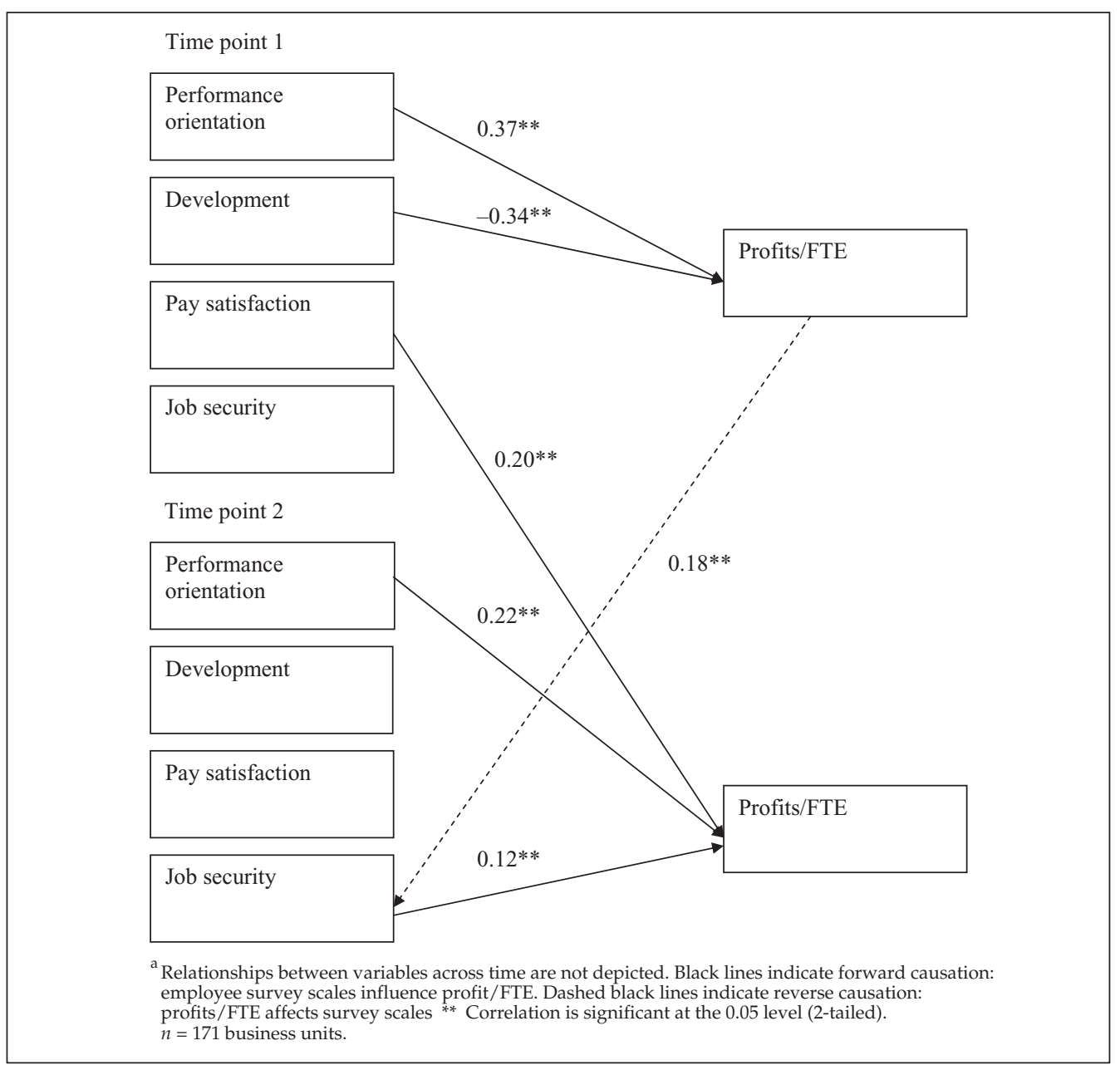

profits/FTE at T1. The employee survey scores collectively account for 10.8 per cent additional explained variance, which we consider a substantial amount.

\section{Euro extrapolation}

In addition to presenting the results in terms of significant beta coefficients and amount of explained variance, we extrapolated the previously mentioned findings to the total sample and the total population. First, we estimated the effect of a one-standard deviation change only for the survey scales for performance orientation and pay satisfaction. Both dimensions were found to be positively predictive of a branch's future performance. Development showed a negative relationship at T1. Job security at T2 was predictive of profits/FTE at T2, although profits/FTE at T1 was found to be more related to job security at T2. We multiplied the standardised coefficient by the standard deviation of the profits/FTE at T2. This showed that a one-standard deviation increase in performance orientation is associated with a 3,120 euro/ 
FTE increase in productivity, and a one-standard deviation increase in pay satisfaction is associated with a 2,840 euro/FTE increase in productivity. Thus, the branches with performance orientation scores of one standard above the mean outperformed those at the mean by a 3,120 euro/FTE increase in productivity. Similarly, the branches with pay satisfaction scores of one standard above the mean outperformed those at the mean by a 2,840 euro/FTE increase in productivity.

Given that the mean of productivity at T2 is 33,216 euros/FTE, the total influence of both survey scales adds up to a 17.9 per cent increase relative to the mean. Adding up the effects of the two employee survey dimensions implies that the branches would need to be able to change these survey scores simultaneously in order to achieve such an upwards change. We tested the feasibility of obtaining these increases by checking the percentage of the branches that had already attained such favourable scores at T2 (plus one standard deviation for both survey scales). It appears that nine per cent of all the branches in our sample had already attained these increases in performance orientation and pay satisfaction by one standard deviation. The branches can thus be expected to attain these levels of scores.

First, we extrapolated these findings to our sample of 171 branches. A 17.9 per cent increase in performance amounts to higher profits of 92 million euros (17.9 per cent of total profits of 512.7 million euros at T2; or 5,960 euros/FTE $\times 15,434$ FTE). The total profits for the entire population (including all the branches) were 994.3 million euros for 2003. Thus, an increase of one standard deviation in pay satisfaction coupled with a similar increase of one standard deviation in performance orientation is associated with an increase in profits of 178 million euros (17.9 per cent increase across the entire company). We have to take into account that we are assuming that all the branches will be able to increase their performance orientation and pay satisfaction scores by one standard deviation. However, the branches that are already achieving high scores might not be able to improve their survey scores by one standard deviation (although in our sample of 171 branches, it was found to be possible to improve their scores by one standard deviation), and moreover, the performance effects might be reduced because of possible ceiling effects.

\section{DISCUSSION}

The aim of this study is to explain performance differences between branches within a large company on the basis of employee survey data in the light of workforce scorecards. In contrast to studies that explain firm-level performance, this study focused on how financial outcomes are achieved via intermediate HRM processes at the branch level. Longitudinal relationships between employee survey data and branch performance were explored. Finding appropriate HRM process indicators, establishing temporal relationships and providing useful management information were identified as major challenges to be addressed. This study has tried to meet these challenges and provide HR researchers and practitioners with an example of the possible answers.

The first challenge concerns the indicators for HRM. In this study, employee survey data were used as an indicator of factors driven by HRM-related interventions. Employees' perceptions, attitudes and behaviours are conceptualised as linking mechanisms in the relationship between HRM activities and outcomes (Boxall and Purcell, 2008; Nishii and Wright, 2008). Hence, research that takes a workers' perspective can contribute to gaining a deeper insight into the HRM-performance relationship (e.g. Guest, 1999). In addition, multiple employee ratings within a branch were averaged, which results in higher reliability scores on HRM processes than is common in studies using a single manager's point of view regarding 
implemented HRM practices (Gerhart, 2007). In line with Nishii et al.'s (2008) study, this study confirms the utility of looking at employee perceptions as indicators of the way HRM policies are enacted in organisations. Survey information is found to be predictive of future financial performance and indicative of the HRM-related processes involved, as will be explained later.

An increase in performance orientation within a branch was associated with an increase in productivity over two years. Branches that are perceived by employees to be more qualityfocused, more cost-effective and that communicate their strategic goals to employees more effectively do achieve higher profits. In these branches, employees are aware of the strategic focus and can align their efforts and behaviours. Pay satisfaction at T1 positively affected productivity at $\mathrm{T} 2$. In this company, the implementation of a new operating system in which job functions are more clearly classified and employees are paid for performance could have been the reason for higher scores on pay satisfaction and over time, may have had the effect of motivating employees to perform better, resulting in higher branch profits.

We found support for an effect of job security (T2) on productivity (T2), and for a reversed relationship. The lagged, reversed effect was slightly stronger than the effect in the longitudinal part (bottom) of the model. High performance might be perceived by the employees as a positive signal with regard to employment security, as proposed by Paauwe and Boselie (2005). On the other hand, employees working in low-performing branches might experience less employment security because the pressure to change in the future is greater in these branches, possibly even threatening their jobs.

Contrary to our expectations, we found a negative relationship between development and productivity. Sending employees on training courses increases costs and might decrease benefits for the duration of the training, while the benefits of the newly acquired knowledge, skills and abilities will only become visible over a longer time period. Cappelli and Neumark (2001) found similar findings with regard to teamwork training.

The second challenge we addressed was how to make temporal inferences between HRM indicators and outcomes. Most of the studies previously carried out did not satisfy the three necessary preconditions for drawing temporal inferences. This study used a longitudinal design with two data waves and applied structural equation modelling; this approach enabled us to at least draw conclusions on temporal order between our variables. We tested the extent to which productivity increased as a result of changes in employee survey dimensions and tested for the possibility that productivity scores influenced employee survey dimensions.

Compared with other longitudinal studies (Ryan et al., 1996; Schneider et al., 2003), we observed fewer inverse relations. However, in line with former studies (Schneider et al., 2003), we found that productivity had a positive effect on job security. With regard to the third and final precondition for establishing causality, the possibility of controlling for or ruling out alternative explanations for a possible causal relationship, this precondition was not fully satisfied in our study. We derived data from a single organisation and thus implicitly controlled for the influence of institutional factors in HRM, which is relatively large in the Netherlands (Boselie et al., 2001) as well as for industry and company effects. However, we could not control for several branch differences such as distribution channels, use of information systems and operational practices. So although we can exclude the effect of institutional, industry and company factors, additional branch-level interventions might be responsible for the relationships found. However, according to Walker et al. (2008), 'between branch' factors have little influence on longitudinal relationships. Branch factors that influence survey scores and productivity in a branch at T1 are also likely to influence survey scores and productivity at T2 in that branch. An exception is time-varying factors. For example, Boxall and Macky (2009) suggested that changes in work and employment practices are often accompanied by related changes in management actions and investments. In 
this study, the branches with high scores on goal effectiveness and quality orientation might also have introduced more advanced operating systems.

Finally, the third challenge we addressed was how to translate established relationships into relevant management information. The most important conclusion to be drawn from this study is that 10.8 per cent of the variance in branch profits/FTE can be explained by scores derived from survey scores on perceptions and attitudes after correcting for prior performance. Existing research did not lead us to expect such a substantial degree of explained variance. This is higher than that found in the longitudinal study by Ryan et al. (1996). This suggests that considerable opportunity for more profitability because of enhanced HRM-related change processes was present over the research period in the organisation we investigated. The difference between average time 1 and average time 2 profitability confirms this statement, although part of this rise in profitability can simply be attributed to market trends. However, the HRM-related changes may be necessary in order to take advantage of an upward trend.

When we translate our results into practical implications, the importance of monitoring employee survey dimensions becomes clear. A one-standard deviation increase in performance orientation and a one-standard deviation increase in pay satisfaction are associated with 178 million euros in higher profits for the entire organisation. Concerning the feasibility of these changes, nine per cent of all the branches managed to obtain these one-standard deviation increases. This indicates that branches can manage to obtain these scores, which in turn suggests there is still room for improvement in profitability for the organisation in the branches that have not yet obtained these scores.

\section{Limitations}

Although the use of two waves of employee survey and performance data in a context of renewed HRM policies is unique in this field of research, the way the longitudinal data coupling was performed in this study has a limitation. We compared different time lags by allowing different time intervals (one to three years); however, this did not affect our results. Theory on the appropriate time lag is lacking. The positive effects of development, for instance, may take longer. Moreover, this time lag may be too short to capture the causal effects of pay satisfaction because the stability of this survey dimension was relatively high. Studies with longer time intervals after actual HRM changes would provide a key area for future research.

The second limitation concerns the measures used in this study. This study compared branches, so individual survey scores had to be aggregated to mean scores at the branch level. Working with aggregated data could be problematic due to the differences in branch size. The standard errors and confidence intervals for the aggregated survey scores might be distorted (Klein et al., 2000). Furthermore, the amount of variance at the branch level (ICC1) was rather low for some survey scales, indicating that these scales are conceptually better suited to the individual, job or team levels rather than the branch level.

\section{Implications}

Practice This research informs HRM practice because this study shows that the benefits of HRM-related change processes can, to a substantial extent, be traced using employee survey information. Our survey measures may not be the causal factors, but they do reflect the processes (proxy measures), and this fits very well with a workforce scorecard perspective, where measures of different kinds and contexts are combined in trying to monitor and manage an organisation's human resources. Survey information is predictive of future financial performance and indicative of the underlying processes involved. Monitoring and managing 
differences in employee survey dimensions is important for organisations. After all, these aspects are performance-stimulating factors that offer line and HR managers better control opportunities than, for example, external factors such as market trends or market prices.

The scores of a particular branch on employee survey dimensions compared with its prior scores and compared with the scores of other branches provide branch managers with useful management information on the branch's current position. The study shows that when employees are aware that the efficient delivery of high quality to customers is given priority in their branch and that they will be rewarded accordingly, this information will guide their behaviour to be in line with this goal, resulting in improved performance. Hence, scores on performance orientations in particular, together with pay satisfaction, are important. This is in line with the recently proposed employee 'line of sight' concept. Line of sight indicates the extent to which an employee understands the organisation's values and objectives, and understands how to effectively contribute to delivering them (Boswell, 2006).

Research This study contributes to our knowledge of the HRM-performance linkage. The assumption that there is no variation in HRM within firms has been challenged in recent years (Wright and Haggerty, 2005; Nishii and Wright, 2008), and in line with these authors' conclusions, this study demonstrates that employee perceptions of HRM show variance within one and the same large organisation. Secondly, this study applied a longitudinal design, which is highly recommended in HRM research (Wright et al., 2005). Moreover, comparing business units within one and the same large organisation is a recommended strategy for future research in studying the HRM-performance link (Wright and Gardner, 2003). To unlock the HRMperformance relationship, additional research is needed using longer time frames and more control variables. More research is also needed on how corporate headquarters'-intended HR policies are implemented by business unit line managers, and on the link between the implemented practices and employees' perceptions (Nishii and Wright, 2008).

However, as Wall and Wood (2005) stated, this requires a big science project. Many organisations possess archival survey and performance data, mostly collected by different departments (human resources, finance and control). Establishing longitudinal relationships between employee survey data and financial outcomes as we did in this study is possible in many other larger organisations. Meta-analysing a series of such large organisation-specific studies or branch of industry-specific studies is one option for future 'big science' in HRM.

\section{Acknowledgement}

The authors wish to thank the Rabobank Group for providing the opportunity to study data and publish the findings. The authors would like to thank Barry Gerhart for his helpful comments.

\section{Note}

1. Including length of time interval as a control variable did not change the pattern of our results. Time interval only had a significant positive effect on performance and development at T2. We therefore decided to report the results of the revised model without including time interval as a control variable.

\section{REFERENCES}

Arbuckle, J. (2005). AMOS (Version 6.0) [Computer program]. Chicago, IL: SPSS.

Becker, B.E. and Gerhart, B. (1996). 'The impact of human resource management on organisational performance: progress and prospects'. Academy of Management Journal, 39: 779-801. 
Becker, B.E., Huselid, M.A. and Ulrich, D. (2001). The HR Scorecard: Linking People, Strategy and Performance, Boston, MA: Harvard Business School.

Boselie, P., Paauwe, J. and Janssen, P. (2001). 'Human resource management and performance: lessons from the Netherlands'. International Journal of Human Resource Management, 12: 1107-1125.

Boselie, P., Dietz, G. and Boon, C. (2005). 'Commonalities and contradictions in HRM and performance research'. Human Resources Management Journal, 15: 67-94.

Boswell, W. (2006). 'Aligning employees with the organisation's strategic objectives: out of "line of sight", out of mind'. International Journal of Human Resource Management, 17: 9, 1489-1511.

Boxall, P. and Macky, K. (2009). 'Research and theory on high-performance work systems: processing the high-involvement stream'. Human Resource Management Journal, 19: 1, 3-23.

Boxall, P. and Purcell, P. (2008). Strategy and Human Resource Management, 2nd edn, Basingstoke: Palgrave Macmillan.

Byrne, B.M. (2001). Structural Equation Modeling with AMOS: Basic Concepts, Applications, and Programming, Mahwah, NJ: Lawrence Erlbaum.

Cappelli, P. and Neumark, D. (2001). 'Do "high performance" work practices improve establishment level outcomes?' Industrial and Labor Relations Review, 54: 737-776.

Combs, J., Liu, Y., Hall, A. and Ketchen, D. (2006). 'How much do high-performance work practices matter? A meta-analysis of their effects on organisational performance'. Personnel Psychology, 59: 3, 501-528.

Cook, D. and Campbell, D. (1979). Quasi-Experimentation: Design \& Analysis Issues for Field Settings, Boston: Houghton Mifflin Co.

Fischer, H. and Mittorp, K.D. (2002). 'How HR measures support risk management: the Deutsche Bank example'. Human Resource Management, 41: 4, 477-490.

Gerhart, B. (2005). 'Human resources and business performance: findings, unanswered questions and an alternative approach'. Management Revue, 16: 2, 174-185.

Gerhart, B. (2007). 'Modeling HRM and performance linkages', in P. Boxall, J. Purcell and P. Wright (eds), The Oxford Handbook of Human Resource Management, New York: Oxford University Press.

Gerhart, B., Wright, P.M. and McMahan, G.C. (2000). 'Measurement error and estimates of the HR-firm performance relationship: further evidence and analysis'. Personnel Psychology, 53: 855-872.

Guest, D. (1997). 'Human resource management and performance: a review and research agenda'. International Journal of Human Resource Management, 8: 263-276.

Guest, D. (1999). 'Human resource management - the worker's verdict'. Human Resource Management Journal, 14: 11, 79-96.

Guest, D. (2001). 'Human resource management: when research confronts theory'. International Journal of Human Resource Management, 12: 1092-1106.

Guest, D.E., Michie, J., Conway, N. and Sheehan, M. (2003). 'Human resource management and corporate performance in the UK'. British Journal of Industrial Relations, 41: 2, 291-314.

Hackman, J.R. and Oldman, G.R. (1975). 'Development of the job diagnostic survey'. Journal of Applied Psychology, 60: 159-170.

Huselid, M.A. (1995). 'The impact of human resource management practices on turnover, productivity, and corporate financial performance'. Academy of Management Journal, 38: 635-672.

Huselid, M.A., Jackson, S.E. and Schuler, R.S. (1997). 'Technical and strategic human resource management effectiveness as determinants of firm performance'. Academy of Management Journal, 40: 1, 171-188.

Huselid, M.A., Becker, B.E. and Beatty, R.W. (2005). The Workforce Scorecard, Managing Human Capital to Execute Strategy, Boston, MA: Harvard Business School Publishing Corporation.

James, L.R. and Demaree, R.G. and Wolf, G. (1984). 'Estimating within-group interrater reliability with and without response bias'. Journal of Applied Psychology, 65: 85-98.

Klein, K.J., Bliese, P.D., Kozlowski, S.W.J., Dansereau, F., Gavin, M.B., Griffin, M.A., Hofmann, D.A., James, L.R., Yammarino, F.J. and Bligh, M.C. (2000). 'Multilevel analytical techniques: 
commonalities, differences, and continuing questions', in K.J. Klein and S. Kozlowski (eds), Multilevel Theory, Research, and Methods in Organisations, San Francisco, CA: Jossey-Bass.

Koys, D.J. (2001). 'The effects of employee satisfaction, organisational citizenship behavior, and turnover on organisational effectiveness: a unit-level, longitudinal study'. Personnel Psychology, 54: $1,101-114$.

Mayo, A. (2001). The Human Value of the Enterprise: Valuing People as Assets, London: Nicholas Brealey Publishing.

Nishii, L. and Wright, P. (2008). 'Variability within organizations: implications for strategic human resource management', in D.B. Smith (ed.), The People Make the Place: Dynamic Linkages Between Individuals and Organizations, New York: Taylor and Francis Group.

Nishii, L., Lepak, D.P. and Schneider, B. (2008). 'Employee attributions of the "why" of HR practices: their effects on employee attitudes and behaviors, and customer satisfaction'. Personnel Psychology, 61: 503-545.

Paauwe, J. (2004). HRM and Performance: Achieving Long Term Viability, Oxford: Oxford University Press.

Paauwe, J. and Boselie, P. (2005). 'HRM and performance: what next?' Human Resource Management Journal, 15: 4, 68-82.

Patterson, M.G., West, M.A., Shackleton, V.J., Dawson, J.F., Lawthom, R., Maitlis, S., Robinson, D.L. and Wallace, A.M. (2005). 'Validating the organisational climate measure: links to managerial practices, productivity and innovation'. Journal of Organizational Behavior, 26: 379408.

Pfeffer, J. (1997). 'Pitfalls on the road to measurement: the dangerous liaison of human resources with the ideas of accounting and finance'. Human Resource Management, 36: 3, 357-365.

Phillips, J.J., Stone, R.D. and Phillips, P.P. (2001). The Human Resources Scorecard: Measuring the Return on Investment, Boston, MA: Butterworth-Heinemann.

Quinn, R.E. and Rohrbaugh, J. (1983). 'A spatial model of effectiveness criteria: toward a competing values approach to organisational analysis'. Management Science, 29: 363-377.

Rousseau, D. (2006). 'Is there such a thing as "evidence based management"'? Academy of Management Review, 31: 2, 256-269.

Ryan, A.M., Schmit, M.J. and Johnson, R. (1996). 'Attitudes and effectiveness: examining relations at an organisational level'. Personnel Psychology, 49: 4, 853-882.

Schneider, B., Hanges, P.J., Smith, D.B. and Salvaggio, A.N. (2003). 'Which comes first: employee attitudes or organisational financial and market performance?' Journal of Applied Psychology, 88: 5, 836-851.

Siehl, C. and Martin, J. (1990). 'Organisational culture: a key to financial performance', in B. Schneider (ed.), Organisational Climate and Culture, San Francisco, CA: Jossey-Bass.

Smith, P., Kendall, L. and Hulin, C. (1969). The Measurement of Satisfaction in Work and Retirement: A Strategy for the Study of Attitudes. Chicago, IL: Rand McNally.

Toulson, P.K. and Dewe, P. (2004). 'HR accounting as a measurement tool'. Human Resource Management Journal, 14: 2, 75-90.

Ulrich, D. (1997). 'Measuring human resources: an overview of practice and a prescription for results'. Human Resource Management, 36: 303-320.

Van Muijen, J., Koopman, P., de Witte, K. and Bast, B. (1996). Focus op Organisatiecultuur: Het Concurrerende Waardenmodel en het Meten en Veranderen van Organisatiecultuur, Schoonhoven: Academic Service.

Van Veldhoven, M. and Meijman, T.F. (1994). Het Meten van Psychosociale Arbeidsbelasting met een Vragenlijst: De Vragenlijst Beleving en Beoordeling van de Arbeid (VBBA), Amsterdam: Nederlands Instituut voor Arbeidsomstandigheden.

Walker, A.G., Smither, J.W. and Waldman, D.A. (2008). 'A longitudinal examination of concomitant changes in team leadership and customer satisfaction'. Personnel Psychology, 61: 547-577.

Wall, T.D. and Wood, S.J. (2005). 'The romance of human resource management and business performance, and the case for big science'. Human Relations, 58: 4, 429-462. 
Wright, P.M. and Gardner, T.M. (2003). 'The human resource-firm performance relationship: methodological and theoretical challenges', in D. Holman, T.D. Wall, C.W. Clegg, P. Sparrow and A. Howard (eds), The New Workplace: A Guide to the Human Impact of Modern Working Practices, Chichester: Wiley.

Wright, P.M. and Haggerty, J.J. (2005). 'Missing variables in theories of strategic human resource management: time, cause, and individuals'. Management Revue, 16: 2, 164-173.

Wright, P.M., Gardner, T.M., Moynihan, L.M. and Allen, M.R. (2005). 'The relationship between HR practices and firm performance: examining causal order'. Personnel Psychology, 58: 2, 409-446. 